\title{
SINGULARIDADES EDUCATIVAS DO FUTEBOL DO RECREIO
}

DOI: 105902/010283088065

Data de Submissão: 07/03/2013 Data de Aceite: 04/12/2013

Cláudia Pereira das Neves

Professora Associada à Rede Municipal de Pelotas clau.perneves@yahoo.com.br

Valdelaine da Rosa Mendes Professora Adjunta da Universidade Federal de Pelotas valrosamendes@uol.com.br

Márcio Bonorino Figueiredo

Professor Associado da

Universidade Federal de Pelotas bonorino.sul@terra.com.br

Luiz Carlos Rigo

Professor Associado da

Universidade Federal de Pelotas

Icrigo@terra.com.br

Resumo: Esta pesquisa tem como justificativa a relevância cultural alcançada pelo futebol moderno e a sua presença no espaço escolar. O objetivo central consiste em fazer uma descrição e uma análise cuidadosa sobre a presença do futebol no recreio escolar. O estudo foi realizado a partir de uma perspectiva da etnografia contemporânea. Através de vinte observações sistemáticas do recreio de uma escola particular da cidade de Pelotas - RS - Brasil e de dezessete entrevistas com crianças da quarta e da quinta séries dessa mesma escola. O estudo apontou que o futebol do recreio, constitui-se em uma importante alteridade pedagógica as disciplinas curriculares.

Palavras-chave: Futebol. Criança. Educação. 


\section{Introdução /Justificativa}

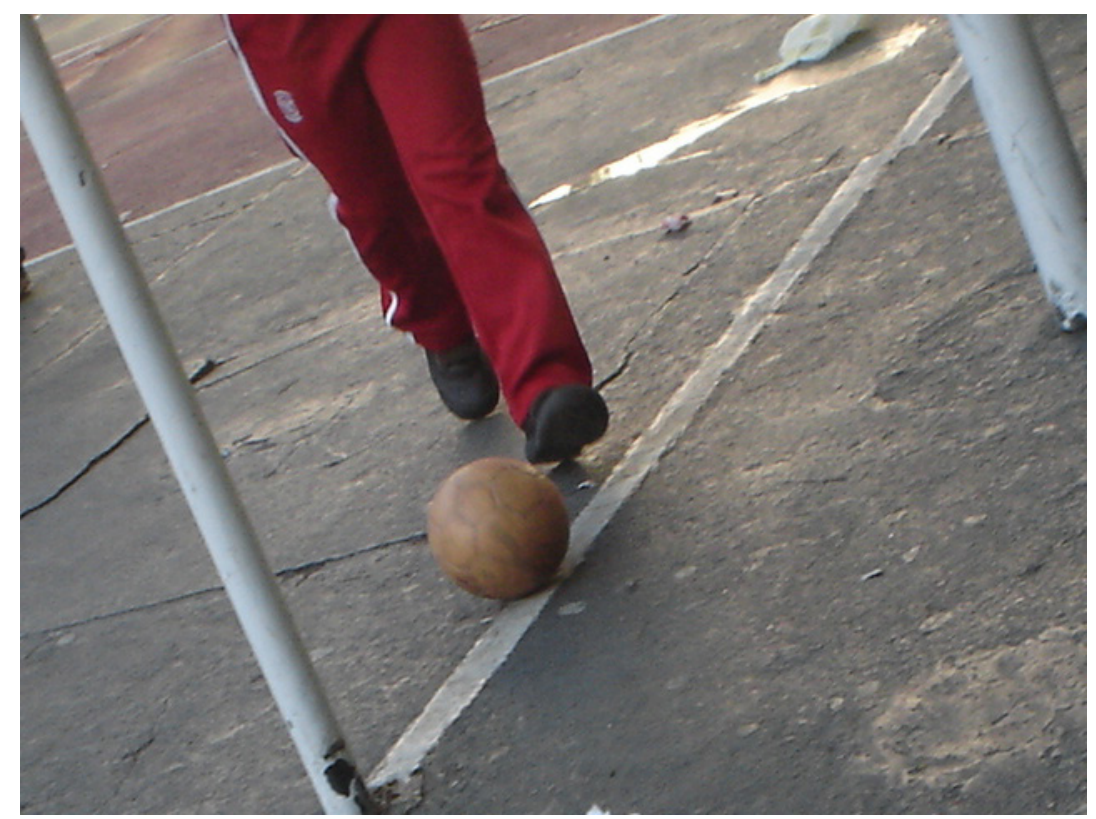

Fig. 01 - O futebol do recreio é um dos momentos mais esperado na escola. (Fonte da fotografia: Diário de Campo do autor, julho de 2009).

Nos últimos anos estamos acompanhando um aumento e uma diversificação das pesquisas do campo da Educação Física e da Educação, que tratam do recreio escolar. Santos Silva, Petroski, e Santos Silva, (2010), por exemplo, abordam questões relacionadas ao sedentarismo e a atividade física durante o recreio escolar. Outros estudos, como Neuenfeld (2009), por exemplo, faz uma análise do recreio escolar a partir de determinados princípios pedagógicos. Inserido nesse contexto de reconhecimento e valorização do recreio escolar essa pesquisa trata especificamente sobre as práticas futebolísticas que ocorrem no recreio de uma determinada escola. Uma justificativa para o estudo está no fato do futebol ser uma das atividades que mais está presente nos recreios escolares, (BURGOS, TORQUIST, BECKMKAMP, 2011; NEUENFELD, 2009).

Assim, esse estudo teve como objetivo central descrever e analisar a presença e as múltiplas configurações educativas que constituem e caracterizam o futebol do recreio em uma escola particular. Levando em consideração a distribuição das séries nos turnos da escola, bem como a disponibilidade de horários para a realização do trabalho de campo, delimitamos o corpus empírico da pesquisa em um dos recreios do turno da tarde ${ }^{1}$.

\footnotetext{
${ }^{1} \mathrm{~A}$ escola estudada possuía dois recreios no turno da tarde: um em que participavam os alunos da educação infantil, até a terceira série do ensino fundamental, e outro que ocorria logo após o primeiro, em que participavam os alunos da quarta até a nona séries do ensino fundamental.
} 


\section{Opções Metodológicas}

Para auxiliar-nos a compreender, descrever e a analisar este futebol do pátio da escola serviram-nos de horizontes questões como: Com que frequência acontece esse futebol? Onde ele ocorre e como costuma estruturar-se? Quais são as suas regras? Quem são os seus praticantes? Que relação eles mantêm com o futebol fora da escola?

Pelas opções teóricas e metodológicas que a pesquisa seguiu, podemos classificá-la como um estudo qualitativo que aconteceu inspirado nos princípios da etnografia contemporânea. Esta, segundo Geertz (1989, p. 19), tem como um dos seus principais objetivos e desafios realizar uma "descrição densa" do fenômeno cultural selecionado para o estudo. Para isso, prossegue Geertz, "o pesquisador pode e deve lançar mão de uma série de procedimentos como: observações, entrevistas, fotografias e outros recursos que julgar procedente". Esses recursos, aliados ao conhecimento e à competência teórica que o pesquisador possui, irão compor o suporte teórico metodológico de seu estudo.

Inspirados nas questões teóricas e metodológicas acima mencionadas, realizamos uma série de 20 observações do recreio do turno da tarde da escola selecionada. As observações ocorreram durante o primeiro semestre de 2009, nos meses de junho e julho e foram registradas em um caderno de campo e enriquecidas com fotografias. Além das observações, realizamos 17 entrevistas semi-estruturadas com meninos das $4^{a}$ e das $5^{\text {a }}$ séries $^{2}$, as turmas que mais jogavam futebol durante o recreio. Estas ocorreram no segundo semestre de 2009, durante os meses de setembro e outubro, após encerrarmos as observações. O roteiro e a preparação dessas entrevistas semi-estruturadas seguiram os procedimentos apontados por Triviños (1987), acrescidos das singularidades e dos cuidados específicos que requerem as entrevistas realizadas com crianças.

A escola em que o estudo foi realizado é uma escola particular ${ }^{3}$, fundada em 1895, localizada na zona central da cidade de Pelotas/RS, Brasil, (por uma preocupação ética preservamos o anonimato da instituição e também das crianças, utilizamos apenas uma

\footnotetext{
${ }^{2} \mathrm{~A}$ escola possui três turmas de quarta série e quatro turmas de quinta série e apenas uma de cada funciona pelo turno da manhã.

${ }^{3}$ Apesar de ser uma escola particular ela não está entre as escolas mais elitizadas da cidade.
} 
inicial fictícia para cada uma delas). Atualmente (2012), a escola conta com aproximadamente 80 professores e 1000 alunos oriundos, predominantemente, da classe média e funciona em dois turnos; pela manhã atende a alunos da quarta série do ensino fundamental ao ensino médio e à tarde atende alunos a partir da educação infantil até a nona série do ensino fundamental.

Além das salas de aula, a escola possui: laboratórios de química, física e biologia, teatro, capela, parque infantil, cantina, sala de literatura infantil, ginásios de esporte, laboratórios de informática, biblioteca, sala de dança, sala de judô, pavilhão de ginástica artística e o pátio, que é o recorte geográfico e arquitetônico central deste estudo.

Para atender aos procedimentos éticos indicados para este tipo de pesquisa além do consentimento da direção da escola foi solicitado que os responsáveis legais por cada uma das 17 crianças respondessem e assinassem um termo de consentimento ${ }^{4}$, autorizando as crianças a responderem a entrevista, a serem fotografadas e a fazerem parte da pesquisa.

\section{Quando o pátio vira o centro do currículo}

O pátio dessa escola localiza-se no centro da mesma e é totalmente cercado pelo prédio onde estão as demais instalações citadas anteriormente. Nele há uma cantina, uma pracinha, duas quadras de mini voleibol no lado direito e ao centro duas quadras poliesportivas calçadas e com as marcações das quadras de futsal, voleibol e basquetebol.

Durante o recreio:

- Surgem três bolas de futebol.

- Enquanto alguns meninos escolhem os times, outros ficam chutando a bola a gol.

- Enquanto os meninos se preparam para os jogos, as meninas formam pequenos grupos e estão passeando e conversando pelo pátio.

- No recreio de hoje se formaram pelo menos cinco grupos de meninos para jogar futebol. Alguns grupos simplesmente correm por todo o pátio disputando a bola, outros se posicionam em meia quadra e começam a jogar uma partida de

${ }^{4}$ Modelo elaborado pela comissão de ética do Programa de Mestrado Em Educação Física da Universidade Federal de Pelotas. 
futebol.

- Os meninos menores correm e se abraçam na hora de comemorar os gols. Já os maiores, da quinta série, fazem uma comemoração mais contida, geralmente batem as mãos e correm para o seu campo de jogo.

- Faltam poucos minutos para o fim do recreio, os cincos monitores do SCT (Serviço de Coordenação de Turno) que cuidam do recreio recolhem as bolas, os meninos saem em direção às suas salas de aula. Parece que o término do jogo é o fim do recreio. Alguns minutos depois toca o sinal (Registro do Diário de Campo de 15 de junho de 2009, 16h) ${ }^{5}$.

Durante as observações, notamos que os meninos utilizam quase toda a área destinada aos esportes existente no pátio da escola. Eles ocupam as duas quadras poliesportivas jogando futebol, as quadras de mini voleibol jogando voleibol e outros espaços do pátio que muitas vezes se transformam em campo de futebol improvisado.

A adaptação ao espaço, a escolha e definição das atividades e regras, a formação de grupos, o convívio com outras faixas etárias fazem do recreio um espaço singular de sociabilidade. Por ser um momento livre de atividades formais, planejadas e direcionadas - em que a solução de conflitos ocorre sem a presença de um adulto ${ }^{6}$ - torna-se locus importante de aprendizagem sobre as relações de poder presentes na vida social.

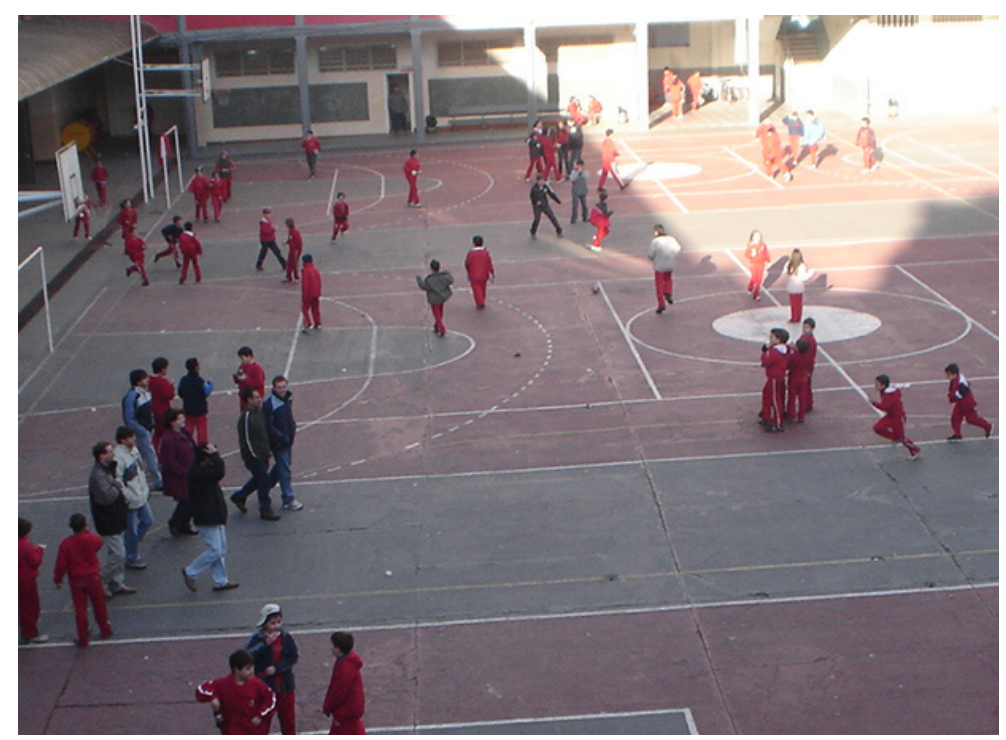

Fig. 02 - Vista panorâmica do pátio da escola em um dia de sol, lugar que as crianças correm, conversam e jogam futebol. (Fonte da fotografia: Diário de Campo do autor, junho de 2009).

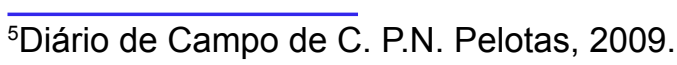

${ }^{6} \mathrm{Na}$ escola há pessoas que observam o recreio, mas não intervêem nas atividades. 


\section{Peculiaridades do futebol do recreio}

Quando se aproximava o recreio, nossa atenção aumentava, saíamos correndo da sala assim que soava a sineta. Poder chegar rápido ao centro do campinho era quase uma garantia de um lugar nos times, uma chance maior de não ficar encostado à trave, esperando a vez ou, o que é pior, sentado como um derrotado. (RIGO, 1999, p.113)

A regularidade da produção de futebol no recreio da escola em questão revela a importância dessa prática no cotidiano dos alunos. Durante os quatro meses em que realizamos o trabalho de campo, observamos que o futebol não aconteceu no recreio das aulas apenas quando estava chovendo. Nas entrevistas, quando perguntamos sobre o recreio nos dias de chuva, os meninos responderam que nesses dias eles não jogavam futebol, mas alguns destacaram que não jogavam apenas devido à restrição da escola, porque "senão a gente jogaria também", salientaram M. e A., ambos alunos de dez anos da quarta série.

Durante o período que estivemos realizando as observações, acompanhamos o recreio também em dias de chuva. Nesses dias, percebemos que a rotina do recreio altera-se um tanto, o número de crianças que vão para o pátio é menor e, como a escola não libera as bolas, as crianças procuram fazer outras atividades, como mostra a descrição que segue:

- Como o dia está úmido e abafado poucas crianças desceram para o pátio. Às $16 \mathrm{~h}$ toca o sinal para o recreio e vários meninos correm para retirar as bolas, mas nenhuma é liberada, eles reclamam muito.

-Observei que apesar de não ter acontecido os jogos de futebol, os meninos que costumam jogar juntos permanecem em seus grupos. Às 16h20min soa a sirene para o fim do recreio e um pouco mais rápido do que os dias de sol o pátio se esvazia. (Registro do Diário de Campo de 07 de julho de 2009).

Dayrell (1996) afirma "que a escola constitui-se de um conjunto de tempos e espaços ritualizados". E acrescenta que "os diferentes comportamentos dos alunos, a relação com os professores, a semana de provas são exemplos desses rituais escolares" (p.16). Como um componente do universo escolar, o futebol do recreio parece ter se tornado mais um ritual escolar, que em dias de sol dura praticamente todo o recreio. 
15h55min - Alguns meninos se reúnem e discutem quem vai pegar uma bola. Um fala 'Eu pego a bola', o outro responde: 'Não, eu pego, senão tu quer mandar no jogo', os dois correm em direção à fila, o que chegou primeiro fica na fila e o outro retorna para a quadra e se coloca junto com os demais, aguardando o início do jogo.

Um dos meninos que está na fila grita: "Tio Henrique, a bola tio Henrique?"A bola é liberada e todos vão para as quadras onde um grupo de colegas está à espera para o jogo. (Registro do Diário de Campo de 02 de julho de 2009).

A passagem acima ressalta a disputa pela bola. Para eles, pegar a bola significa um lugar garantido no time e a possibilidade de deliberar sobre a formação das equipes e a posição em que cada um irá jogar. Os jogos geralmente acontecem em meia quadra, já que a disputa por um lugar é grande; somente em dois dias de observações ocorreram jogos em uma quadra inteira. O espaço das quadras é feito de tal forma que o maior número de times possam jogar.

Quando alguém não consegue um lugar no time escolhido, resta esperar que sobre uma vaga. Algumas vezes, o número de jogadores nos times é mais flexível e dessa forma pode "entrar sem pedir; às vezes a gente entra e diz to jogando e deu", (H. dez anos, quinta série). Outra alternativa, é jogar em outros lugares do pátio, conforme disse B. (nove anos, quarta série): "quando um vai pegar a bola os outros ficam guardando lugar, mas quando não dá a gente joga em qualquer lugar". "A gente joga em meia quadra, se der, na quadra inteira ou se não a gente joga no portão", completou F. (dez anos, quinta série).

Durante as observações foi possível perceber que no recreio ocorre uma maximização dos espaços do pátio em prol do futebol:

Todas as quadras são ocupadas, acontecem quatro jogos ao mesmo tempo, também há um grupo de meninos jogando em um canto do pátio que utiliza uma janela protegida com uma grade como gol. Apesar de ser um local pequeno e restrito, eles jogam com a mesma disposição dos meninos que possuem uma quadra para jogar. (Registro do Diário de Campo de 17 de julho de 2009). 
A constituição dos grupos que jogam futebol no recreio foi outro ponto que se destacou durante as observações. Geralmente há uma divisão por série, os alunos das quartas séries jogam entre si e o mesmo ocorre com os das quintas séries. Como já foi exposto anteriormente em um dos trechos do Diário de Campo, nos dias em que o jogo não acontece, como nos dias de chuva, os grupos que jogam futebol costumam permanecer juntos em outras atividades. Sobre isso Dayrell (1996, p.14) afirma que a “(...) escola é um espaço coletivo, de relações grupais. O pátio, os corredores, a sala de aula materializam a convivência rotineira de pessoas".

Os grupos de meninos que sempre jogam juntos parecem pertencer à mesma turma e mostram resistência quando meninos de outras turmas pedem para jogar com eles, principalmente se os que pedem para jogar são de menor idade. Nos dias em que a bola não é liberada, os meninos que costumam jogar juntos fazem outras atividades como correr, jogar bafo $^{7}$ ou conversar.

As entrevistas que realizamos mostraram que nas práticas do futebol do recreio predomina uma sociabilidade constituída a partir dos parâmetros da idade ou da série. Quando perguntei sobre como eles reagiam quando alguém que não era do grupo pedia para jogar com eles, B. (dez anos, quarta serie) respondeu: "Deixo, normal. É, mas não pode ser muito maior, tem que ser mais da minha turma". Outros comentaram: "A gente deixa. Só quando é muito velho ou muito novo não; um ano mais velho ou um ano mais novo a gente deixa", J. (dez anos), N. (dez anos) e G. (nove anos) da quarta série.

\subsection{A regra não é clara}

A escola é uma instituição regrada. Como analisou Dayrell (1996, p. 12), "desde a forma da construção até a localização dos espaços, tudo é delimitado formalmente, segundo princípios racionais, que expressam uma expectativa de comportamento dos seus usuários". Na escola observada, uma das regras mais visíveis é a obrigatoriedade do uniforme. Prevista no estatuto disciplinar, quando essa regra é descumprida a punição é a advertência verbal e o registro na ficha atitudinal do aluno.

\footnotetext{
${ }^{7}$ Jogo tradicional realizado com figuras de jogadores de álbum de futebol.
} 
Apesar dessa rigidez, os alunos conseguem ir para a escola vestindo a camiseta do seu time, principalmente nos dias de jogo.

Hoje à noite (24/06/2009 às 21 h 50 min) o Grêmio, F. P enfrentará o Cruzeiro E. C. em Belo Horizonte (MG), em jogo da semifinal da Taça Libertadores da América. Vários alunos estão com a camiseta do Grêmio por baixo do casaco do abrigo (uniforme), que fica aberto durante todo o recreio como uma identificação do pertencimento clubista de cada um. (Registro do Diário de campo de 24 de junho de 2009).

Sexta-feira é o dia que a escola não exige uniforme. Assim, além dos dias de jogos, nas sextas feiras é o dia em que um número maior de crianças costuma ir para a escola vestindo a camiseta do time para o qual torcem. Durante as entrevistas, quando perguntamos se eles iriam de camisetas para a escola, eles responderam: "Só na sexta-feira e quando o Inter vence", F. (dez anos, quinta série); "Sexta ou quando o meu time ganha algum jogo também.", B. (nove anos, quarta série); "Sim, se o time perde, o que for, eu coloco pra incentivar o time"; "Sexta-feira pode, mas eu venho quase todos os dias por baixo do casaco", D. (11 anos) e J. (dez anos) da quinta série.

O futebol do recreio atua como um antídoto a tendência que acompanha a escola moderna de isolar a escola do mundo, como evidenciam os muros que demarcam "a passagem entre duas realidades: o mundo da rua e o mundo da escola" (DAYRELL, 1996, p. 13).

Nas observações feitas foi possível diagnosticar que o futebol que é praticado durante o recreio da escola, ao mesmo tempo em que é constituído por uma série de regras, normas e códigos de condutas próprios daquele espaço, é oxigenado e mantém forte vínculo com o futebol que é vivido pelos alunos fora da escola. A maneira que os alunos fazem uso de algumas regras do futebol adaptando-as para o futebol do recreio é um exemplo disso. Durante as observações, notamos que nos jogos do recreio a partida somente é interrompida para a cobrança de lateral quando a bola sai para bem longe da quadra, caso contrário o jogo continua normalmente. Há momentos no recreio em que os jogos se cruzam; a bola de um jogo invade o outro jogo e mesmo assim ambos os jogos continuam sem interrupção.

Nas entrevistas, ao perguntarmos aos alunos sobre as regras do futebol do recreio, 
predominaram respostas como a de E. (dez anos, quarta série) que disse: "Sim, aqui não tem regra, aqui a bola não sai. Aqui, na falta bota a bola no chão e segue o jogo, não tem lateral, o jogo segue até voltar pra dentro da quadra de novo".

Outro elemento da cultura futebolística que apareceu no futebol do recreio e que Faria (2008) assinala como uma das singularidades do processo de aprendizagem infanto-juvenil do futebol, são as reproduções e as invenções de pequenos jogos de futebol. Sobre a presença desses jogos de futebol no recreio os alunos citaram como exemplo: Três dentro e três fora; Paulistinha, Três e um, etc. Ainda sobre isso, D. (11 anos), J. (11 anos), H. (dez anos) e J. (dez anos) da quinta série comentaram: "na Educação Física a gente joga o futebol certinho e aqui a gente joga Três dentro e três fora, que é assim: tem que levantar a bola e bater por cima".

Essa pluralidade de jogos durante o recreio vai ao encontro do que aponta Rigo (1999, p.118), quando comenta que no universo escolar "o jogo de futebol apresenta-se marcado por microdiversidades culturais, capazes de produzir alterações, inclusive estruturais, sobre o esporte futebol". Assim, no futebol do recreio acontece algo similar ao que acontece em outros lugares de práticas do futebol, em que os "jovens aprendem a 'afinar' os movimentos do corpo, ajustando-se e ao mesmo tempo, produzindo o contexto futebolístico" (FARIA, 2008, p. 213). A invenção e a reprodução de jogos do universo futebolístico, aliado com a flexibilidade das regras e com a mudança dos elementos estruturais do esporte futebol (oficial), que se ajusta aos espaços e ao tempo do recreio escolar (15 minutos), mostra como os alunos também são capazes de ser autores, das práticas futebolísticas que ocorrem durante o recreio escolar.

\subsection{A quadra é dos meninos}

A partir das observações identificamos que os meninos costumavam ocupar mais os espaços físicos do pátio durante o recreio do que as meninas. Essa constatação vai ao encontro do que sinalizam outros estudos que tratam especificamente do gênero e a ocupação do pátio durante o recreio, como os realizados por, por exemplo, por Barrie Thorne apud Wenetz e Stigger (2006, p. 69), que ao analisar a ocupação do pátio em 
escolas americanas, observou que "os meninos ocupavam dez vezes mais espaços que as meninas, principalmente os espaços esportivos."

Essa realidade, entre tantos outros aspectos, ajuda a mostrar como se constroem as diferenças de cultura esportiva entre meninas e meninos, evidenciando como essas diferenças resultam muito mais de determinados estado sociocultural e não de uma disposição biológica, (WENETZ; STIGGER, 2006). Sobre isso, Altmann (1998, p. 26) acrescenta que "(...) o esporte é um meio de os meninos exercerem domínio de espaço da escola", segundo essa mesma autora, as meninas resistem a essa dominação brincando de jogos não esportivos. De todos os recreios observados, apenas em um identificamos a participação de uma menina jogando futebol junto com os meninos. Ela pertencia ao ensino médio e mostrava uma boa habilidade futebolística. Nesse caso, o capital futebolístico dessa menina se sobrepunha a outros critérios como o de idade; série ou mesmo de sexo e a credenciava a participar do futebol jogo. As demais meninas da escola geralmente jogavam voleibol ou passavam o recreio caminhando e conversando em pequenos grupos.

Pelas observações notamos que os meninos se utilizam do fato de, em sua grande maioria, possuírem uma maior experiência futebolística para se impor perante as meninas para ocuparem os espaços esportivos do pátio da escola durante o recreio. Mas, qual a proveniência desse capital futebolístico que os meninos levam para dentro da escola e fazem uso principalmente durante o recreio, produzindo uma distinção de gênero? Para compreender um pouco sobre como se constituem essas diferenças culturais futebolísticas já na quarta e na quinta séries do ensino fundamental, realizamos uma série de perguntas a 17 meninos que participavam intensamente do futebol do recreio.

Quando perguntamos a eles quando começaram a gostar de futebol, as respostas foram: "Desde pequeno", B. (dez anos, quarta série), "desde os meus dois anos", G. (11 anos, quinta série). Com as perguntas que realizamos foi possível observar que, apesar das diferenças existentes entre os meninos, todos eles conviviam com o futebol desde cedo e traziam para o recreio escolar, este capital futebolístico, construído a partir vivências que antecedem e extrapolam a escola formal.

Ao serem perguntados sobre a influência que tiveram para se iniciarem no futebol fora e anterior a escola os meninos destacaram a influência das suas relações parentais, 
principalmente o pai. Como disse B. (nove anos, quarta série), "Desde pequeninho, assim, meu pai já me dava a bola pra eu ficar chutando". Dos 17 meninos entrevistados, apenas um deles relatou que não foi o seu pai, e sim o seu avô, quem primeiro o ensinou a gostar de futebol. Além de incentivar e ensinar a jogar (primeiro professor), o pai aparece também como aquele que mais teve influência na escolha do seu time de futebol. Todos relataram que escolheram o seu time de futebol por influência do pai. "Meu pai escolheu, é de família"; "É de família também"; "Meu pai”, M. (dez anos), P. (nove anos) e A. (dez anos), alunos da quarta série. Os depoimentos das crianças mostram que os pais possuem uma presença marcante na iniciação futebolística dos filhos ${ }^{8}$.

O fato da maioria dos meninos brasileiros serem introduzidos desde cedo de forma mais intensa e em maior quantidade em um universo futebolístico que envolve assistir futebol, construir um sentimento clubista (torcer por um determinado clube) e praticar futebol desde tenra idade, faz com que, em sua maioria os meninos adquiram fora da escola um capital futebolístico maior que as meninas. Essa diferença, oriunda das experiências futebolísticas ainda condicionadas por um forte "ethos de masculidade" (SCHARAGRODSKY, 2002), é transportada para dentro da escola e contribui para os meninos apropriarem-se do pátio e excluir as meninas do futebol.

\section{Considerações Finais}

Após o término deste estudo concluímos que o futebol do recreio em muitos aspectos difere-se do futebol praticado nas aulas de educação física e nos treinos de equipes de escolares, onde há uma influência maior do professor. No recreio há uma maior possibilidade de os alunos lançarem mão daquilo que Mclaren (1991) denominou de "conhecimentos de esquina de rua", que são os saberes que os alunos levam da rua para dentro da escola. Mas, para fazer parte do futebol do recreio, os "conhecimentos de esquina de rua" terão que passar pelo crivo do grupo de alunos que todos os dias ocupam o pátio da escola. A "regra" que estipula que o primeiro a pegar a bola tem o direto de montar o seu time,

\footnotetext{
${ }^{8}$ Em um estudo especifico sobre as relações parentais RIGO et al. (2007) mostraram como muitos país costumam ter uma influência incisiva perante seus filhos quando estes estão matriculados em escolinhas de futsal, principalmente nas categorias de pré-mirim e mirim.
} 
evidencia como o futebol do recreio acontece a partir de acordos do pátio.

Por outro lado, o futebol do recreio também reproduz códigos de outras práticas futebolísticas, como é o caso, por exemplo, da exclusão das meninas. Essa segregação de gênero em parte mantém-se tão enfática porque no Brasil ainda predomina a ideia de que a prática do futebol é um "território exclusivamente masculino", (GUEDES; OLIVEIRA FILHO; NOVAES, 2004, p. 177).

As observações de campo nos mostraram também que para muitos meninos da escola o futebol é o acontecimento do recreio. Munidos de uma bola, eles travam grandes jogos em 15 minutos, experiências que certamente ficarão registradas em suas memórias afetivas escolares.

Assim, um pouco diferente do alerta que faz Neuenfeld (2003) quando descreve o recreio da escola por ele observado como um lugar impróprio para educação, o futebol do recreio que acompanhamos pode ser definido como uma alteridade pedagógica as disciplinas curriculares, mas que também é fundamental para a escola. Apesar de em muitos aspectos diferenciar-se das práticas futebolísticas das aulas de Educação Física, ao menos para um grupo de alunos, o futebol do recreio é uma "experiência educativa" (BONDÍA, 1999), ele representa a possibilidade da vivência de uma sociabilidade que é negociada no pátio da escola.

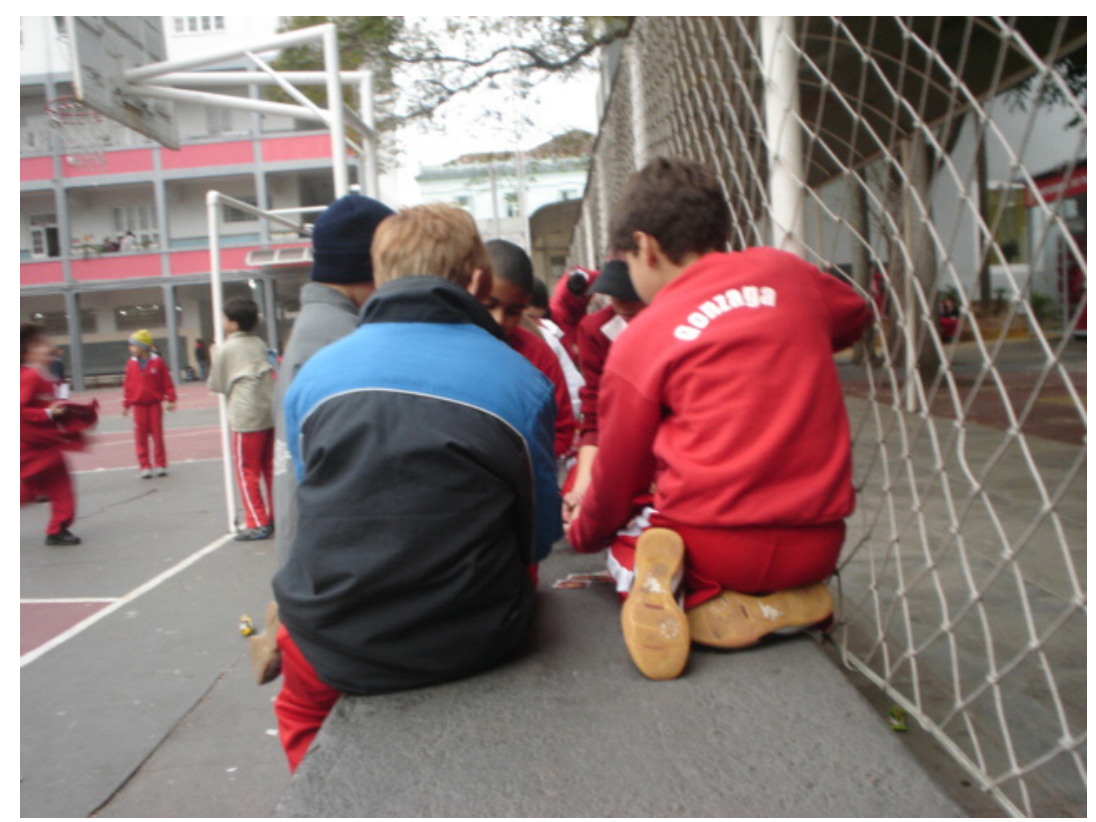

Fig. 03 - Além do jogo de futebol, observamos que o jogo de Bafo e as trocas de figurinha de álbuns de futebol eram outras práticas do universo futebolístico que aconteciam com frequência durante o recreio (Fonte da fotografia: Diário de Campo do autor, julho de 2009). 


\section{Referências}

ALTMANN, H. Rompendo Fronteiras de Gênero: Marias (e) Homens na Educação Física. 1998, 130 f. Dissertação (Mestrado). Curso de Educação. Faculdade de Educação, UFMG, Minas Gerais, 1998.

BONDÍA, J. L. Notas sobre a experiência e o saber da experiência. Revista Brasileira de Educação, Rio de Janeiro, n 19, p. 20 -28, jan/abr. 2002. Disponível em: http://www. anped.org.br/rbe/rbedigital/rbde19/rbde19_04_jorge_larrosa_bondia.pdf. Acessado: 16 de Janeiro de 2011.

BURGOS, M. S.; TORQUIST, L.; BECKMKAMP, D. Brincadeiras praticadas no recreio escolar e nas horas de lazer: Los juegos que se realizan en el recreo escolar y en las horas de recreación. EF Deportes. Revista Digital. Ano 16, n. 156, Mayo de 2011, Buenos Aires. Disponível em: http://www.efdeportes.com/efd156/brincadeiras-praticadas-no-recreioescolar.htm. Acessado: 10 de Janeiro, 2012.

DAYRELL, J. A escola como espaço sócio cultural. In: DAYRELL, J. (org.). Múltiplos olhares sobre educação e cultura. Belo Horizonte: Ed. UFMG, 1996.

FARIA, E. L. A aprendizagem da e na prática social: Um estudo etnográfico sobre as práticas de aprendizagem do futebol em um bairro de Belo Horizonte. 2008, 229 f. Tese (Doutorado). Curso de Educação - Faculdade de Educação, UFMG, Minas Gerais, 2008.

GEERTZ, C. A interpretação das culturas. Rio de Janeiro: Ed. LTC, 1989.

GUEDES, S. L.; OliVEIRA FILHO, P. P. A. NOVAES, R. B. Meninos e meninas no campo de futebol: concepções de gênero em um projeto social. In: GUEDES. S. L. (Org.). Gênero e sexualidade: estudo em trono da Pesquisa Social Brasileira (PESB). Niterói: Intertexto, 2004. p. 151-181.

MCLAREN, P. Rituais na escola: em direção a uma economia política dos símbolos e gestos na educação. Petrópolis, RJ: Vozes, 1991.

NEUENFELD, D. J. Recreio Escolar: o que acontece longe dos olhos dos professores. Revista da Educação Física /UEM. Maringá, v. 14, n. 1, p. 37 - 45, 2003. Disponível em: http://periodicos.uem.br/ojs/index.php/RevEducFis/issue/iew/190/showToc. Acesso em 20/12/2009. 
RIGO, L. C. Futebol 1 X 0 Escola. Cadernos de Educação. v. 8, n. 13, p. 111 - 130, ago./dez. 1999.

RIGO, L. C. et al. Relações parentais no futebol de salão: a experiência do Paulista Futebol Clube. Movimento, Porto Alegre, v. 13, n. 02, p. 77 - 90, 2007. Disponível em: http://seer.ufrgs.br/Movimento/article/view/3547/1948. Acessado em 26 de junho de 2009.

SCHARAGRODSKY, P. A. Los graffitis y los cánticos futboleros platenses: o acerca del proceso de configuración de diversas masculinidades. Revista Brasileira de Ciências do Esporte. v. 24, n. 1. p. 179 - 197. Set. 2002. Campinas autores associados, p. 179-198. Disponível em: http://www.rbceonline.org.br/revista/index.php?journal=RBCE\&page=issue \&op=archive. Acessado em 10 de dezembro de 2009.

SANTOS SILVA, D. A.; DOS SANTOS SILVA, R. J.; PETROSKI, E. L. Comportamento sedentário no recreio escolar e fatores sóciodemográficos associados. Revista da Educação Física/UEM. Maringá, v. 21, n. 2, p. 255-261, 2 trim. 2010. Disponível em: http:// www.periodicos.uem.br/ojs/index.php/RevEducFis/article/view/8321/6056. Acessado em: 20 de novembro de 2010.

TRIVIÑOS, A. N. S. Introdução à pesquisa em ciências sociais: a pesquisa qualitativa em educação. São Paulo: Atlas, 1987.

WENETZ, I. A; STIGGER, M. P. Construção do gênero no espaço escolar. Movimento, Porto Alegre, v. 12, n. 01, p. 59-80, jan. 2006. Disponível em: http://seer.ufrgs.br/Movimento/ article/view/2891. Acessado em 14 de dezembro de 2009. 


\section{SINGULARIDADES EDUCATIVAS DEL FÚTBOL EN EL MOMENTO DEL RECREO}

Resumen: Esta investigación se justifica por la relevancia cultural alcanzada por el fútbol moderno y su presencia en la escuela. El objetivo principal es hacer una descripción y un análisis cuidadoso acerca de la presencia del fútbol en el momento del recreo. El estudio fue realizado a partir de la perspectiva de etnografía contemporánea. Fueron hechas veinte observaciones sistemáticas del recreo en una escuela privada en la ciudad de Pelotas RS - Brasil y también diecisiete entrevistas con niños de los cuarto y quinto años de la misma escuela. El resultado apuntó que el fútbol del recreo, se constituye una alteridad pedagógica para los componentes curriculares.

Palabras-clave: Fútbol. Niño. Educación

\section{EDUCATION SINGULARITIES OF SCHOOL TIME-BREAK SOCCER}

Abstract: This research is justified by the cultural relevance that the modern soccer has achieved and its presence in school. The main goal of the study is to make a description and careful analysis about the soccer in the school time-break. It was conducted from a perspective of contemporary ethnography. Through twenty systematic observations of the time-break in a Pelotas - RS - Brazil private school and seventeen interviews with children of the fourth and fifth grades of this same school. The results founded that the soccer in the time-break, it constitutes an pedagogic otherness curricular subjects.

Keywords: Soccer. Child. Education. 